\title{
2017 Global Initiative for Chronic Obstructive Lung Disease reclassifies half of COPD subjects to lower risk group
}

This article was published in the following Dove Press journal: International Journal of COPD

\author{
Marieann Högman' \\ Johanna Sulku 2,3 \\ Björn Ställberg ${ }^{4,5}$ \\ Christer Janson' \\ Kristina Bröms ${ }^{3,4}$ \\ Hans Hedenström 6 \\ Karin Lisspers ${ }^{4,5}$ \\ Andrei Malinovschi ${ }^{6}$ \\ 'Department of Medical Sciences, \\ Respiratory, Allergy and Sleep \\ Research, ${ }^{2}$ Department of \\ Pharmaceutical Biosciences, Uppsala \\ University, Uppsala, ${ }^{3}$ Center for \\ Research \& Development, Uppsala \\ University/Region Gävleborg, Gävle, \\ ${ }^{4}$ Department of Public Health and \\ Caring Sciences, Family Medicine \\ and Preventive Medicine, Uppsala \\ University, Uppsala, ${ }^{5}$ Center for \\ Clinical Research, Uppsala University, \\ County Council Dalarna, Falun, \\ ${ }^{6}$ Department of Medical Sciences, \\ Clinical Physiology, Uppsala University, \\ Uppsala, Sweden
}

Background: Unlike the 2014 guidelines, the 2017 Global Initiative for Chronic Obstructive Lung Disease (GOLD) guidelines have removed lung function from the risk assessment algorithm of patients with COPD. The aim of this investigation was to analyze the proportion of subjects who would change to a lower risk group when applying GOLD ${ }^{2017}$ and determine if they exhibit different characteristics in terms of inflammation, symptoms and comorbidity compared to the subjects who would remain in a high-risk group.

Subjects and methods: A total of 571 subjects with physician-diagnosed and spirometryverified COPD were included in the present study. The data consisted of measurements of lung function, inflammatory markers, together with questionnaires that covered comorbidities, COPD symptoms and medication.

Results: From group C, 53\% of the subjects would be reclassified to the lower risk group A, and from group D, 47\% of the subjects would be reclassified to the lower risk group B when using GOLD ${ }^{2017}$ instead of GOLD ${ }^{2014}$. Compared to the subjects who would remain in group D, those who would change to group B were more often men ( $56 \%$ vs $72 \%$ ); of an older age, mean (SD), 71 (8) years vs 68 (7) years; had more primary care contact (54\% vs 33\%); had lower levels of blood neutrophils, geometrical mean (95\% CI), $5.3(5.0,5.7)$ vs $4.6(4.3,4.9)$; reported less anxiety/depression ( $20 \%$ vs 34\%); experienced less asthma ( $29 \%$ vs $46 \%$ ) and had fewer symptoms according to the COPD assessment test,16 (5) vs 21 (7). All $p$-values were $<0.05$. Conclusion: The removal of spirometry from risk assessment in GOLD ${ }^{2017}$ would lead to the reclassification of approximately half of the subjects in the risk groups $\mathrm{C}$ and $\mathrm{D}$ to the lower risk groups A and B. There are differences in age, gender, health care contacts, inflammation, comorbidity and symptom burden among those changing from group $\mathrm{D}$ to group $\mathrm{B}$. The effects of reclassification and changes in eventual treatment for disease control and symptom burden need further investigation.

Keywords: COPD, lung function test, eosinophils, neutrophils, comorbidity, GOLD

\section{Introduction}

COPD is a complex disease that is manifested in different ways. Therefore, it is challenging to develop a disease-staging system for the assessment of disease severity and for defining treatment algorithms in COPD. In 1998, the Global Initiative for Chronic Obstructive Lung Disease (GOLD) was formed to set the standards for the evaluation and treatment of the disease. In the first report published in $2001,{ }^{1}$ the severity of COPD was assessed on a grading scale of 1-4 and was based solely on lung function, eg, forced expiratory volume in 1 second $\left(\mathrm{FEV}_{1}\right)$ as percent predicted. However, COPD is a heterogeneous disease with a variation in symptom burden and
Correspondence: Marieann Högman Department of Medical Sciences, Respiratory, Allergy and Sleep Research, Uppsala University, University Hospital, S 75185 Uppsala, Sweden

Tel +46708664153

$\mathrm{Fax}+46186110228$

Email marieann.hogman@medsci.uu.se (c) (1) (5) 2018 Högman et al. This work is published and licensed by Dove Medical Press Limited. The full terms of this license are available at https://www.dovepress.com/terms.php (c) $\mathrm{BY}$ and incorporate the Creative Commons Attribution - Non Commercial (unported, v3.0) License (http://creativecommons.org/licenses/by-nc/3.0/). By accessing the work you hereby accept the Terms. Non-commercial uses of the work are permitted without any further permission from Dove Medical Press Limited, provided the work is properly attributed. For permission for commercial use of this work, please see paragraphs 4.2 and 5 of our Terms (https://www.dovepress.com/terms.php). 
exacerbation frequency that is not always related to lung function impairment. ${ }^{2}$ In addition, the patient's health status is largely related to the symptom burden and the exacerbation frequency. ${ }^{3}$ Therefore, in 2011, the GOLD severity classification was updated by combining the stages $1-4$ based on lung function together with symptom burden that was assessed either by the COPD Assessment Test $(\mathrm{CAT})^{4}$ or by the modified British Medical Research Council (mMRC) scale, ${ }^{5,6}$ together with the exacerbation history. Based on this, the patients were classified into groups A-D. In the 2014 GOLD report, the definition of frequent exacerbation changed slightly to also include $\geq 1$ exacerbations leading to a hospital admission. In 2017, there was a new update in the GOLD classification where the risk assessment into groups A-D was based solely on the symptom burden and exacerbation history, whereas spirometry was used only to grade the patient's airflow limitation from 1 to $4 .^{7}$ Therefore, the subjects classified as belonging to higher risk GOLD C or D group according to GOLD ${ }^{2014}$, which was based solely on poor lung function (eg, $\mathrm{FEV}_{1}<50 \%$ predicted), will be expected to change to the lower risk A or B group according to GOLD ${ }^{2017}$.

The aim of this investigation was to analyze the proportion of subjects who would change to a lower risk group when applying GOLD ${ }^{2017}$ and determine if they exhibit different characteristics in terms of inflammation, symptoms and comorbidity compared to the subjects who would remain in a high-risk group.

\section{Subjects and methods Study design and research subjects}

The Tools Identifying Exacerbations in COPD study is a multidisciplinary prospective study from central Sweden. Participants with a diagnosis of COPD (ICD codes J44.0, J44.1, J44.8 and J44.9) coming from primary and secondary care settings in the central Swedish regions of Dalarna, Gävleborg and Uppsala were recruited and investigated from September 2014 to September 2016. Generally, the research nurse obtained data regarding the regularity of primary or secondary health care contacts at the time of the study visit. If necessary, data were also extracted from the medical records. The diagnosis was confirmed by spirometry, using postbronchodilator $\mathrm{FEV}_{1}$ divided by the highest vital capacity (VCmax) value from a slow (slow vital capacity [SVC]) or forced maneuver (forced vital capacity [FVC]) with a ratio of $<0.70$. The predefined exclusion criterion was history of severe comorbidity, eg, metastasized cancer, severe heart failure or severe angina pectoris, after clinical assessment at the inclusion visit. Since none of the subjects fulfilled such a criterion, no such exclusions were made. In the cases when an exacerbation had occurred, the study visit was delayed by 4 weeks. The included subjects had been/will be invited to participate in two follow-up visits (after 1 year and 2 years). The current analysis is based on the inclusion data.

\section{Data collection}

Inclusion data were collected from one visit that included questionnaires, calculations of body mass index (BMI), as well as measurements of lung function, exhaled carbon monoxide and exhaled nitric oxide together with blood cell counts.

\section{Questionnaires}

$\mathrm{CAT}^{4}{ }^{4} \mathrm{Clinical}$ COPD Questionnaire $(\mathrm{CCQ})^{8}$ and $\mathrm{mMRC}^{5,6}$ were used together with questions regarding demographics, comorbidities, smoking habits, educational level, contacts with the health care system and any prescribed courses of oral corticosteroids or antibiotics. Regular use of long-acting $\beta_{2}$-agonist (LABA), long-acting muscarinic antagonist (LAMA), inhaled corticosteroids (ICS) and their combinations was addressed in a questionnaire. During the study visit, a research nurse went through the answers to the questionnaires with the subjects.

\section{Anthropometry and body composition}

BMI was calculated from height and weight measurements taken at the visit.

\section{Spirometry}

A postbronchodilator spirometry (15 minutes after administration of $400 \mu \mathrm{g}$ salbutamol $)^{9}$ was performed using either a SpiroPerfect Spirometer (Welch Allyn, Skaneateles Falls, NY, USA) or a Jaeger MasterScreen PFT (Erich Jaeger GmbH, Würzburg, Germany). FEV ${ }_{1}, \mathrm{FVC}$ and SVC were measured. $\mathrm{FEV}_{1}$ and $\mathrm{FVC}$ values were also expressed as percent predicted using Swedish reference values. ${ }^{10,11}$

\section{Smoking history}

Smoking habits were addressed in a questionnaire. Measurements of exhaled carbon monoxide (Smoke Check; Intramedic AB, Sollentuna, Sweden) were performed. In the subjects $(n=2)$ who did not answer the smoking questions, exhaled carbon monoxide was used to determine current smoking status (defined as levels $>10$ parts per million).

\section{Inflammatory markers}

Exhaled nitric oxide at an exhalation flow of $50 \mathrm{~mL} / \mathrm{s}$ $\left(\mathrm{F}_{\mathrm{E}} \mathrm{NO}_{50}\right)$ was measured with NIOX VERO (Circassia AB, 
Solna, Sweden), NIOX Flex (Aerocrine AB, Solna, Sweden) or Eco Medics CLD 88 (Eco Medics, Duernten, Switzerland). The measurements were performed in accordance with current recommendations. ${ }^{12}$

Blood neutrophil count (B-Neu) and blood eosinophil count (B-Eos) were analysed (Cell-Dyn 4000; Abbott Laboratories, Abbott Park, IL, USA and Sysmex XN-10; Sysmex America, Inc., Lincolnshire, IL, USA).

\section{Exacerbation}

Exacerbation was defined as acute health care visits, a course of oral corticosteroids and/or a course of antibiotics due to COPD deterioration (based on a questionnaire). Frequent exacerbation was defined as having at least two exacerbations and/or at least one hospital admittance (information retrieved from hospital records) due to a COPD exacerbation during the last year.

\section{Classification of COPD severity}

The subjects were classified using spirometry by $\mathrm{FEV}_{1} \%$ predicted; GOLD grade $1 \geq 80 \mathrm{FEV}_{1} \%$ predicted, GOLD grade 2 50-79 $\mathrm{FEV}_{1} \%$ predicted, GOLD grade $330-49 \mathrm{FEV}_{1} \%$ predicted and GOLD grade $4<30 \mathrm{FEV}_{1} \%$ predicted. The GOLD risk assessment version 2014 A-D and GOLD version 2017 A-D were used to further stratify the participants. Symptom assessment with CAT was used for risk stratification, and a CAT-score $\geq 10$ was a threshold for a high symptom burden. For exacerbation history, we used the definition of frequent exacerbation previously defined.

\section{Ethical approval}

The Regional Review Board in Uppsala, Sweden (Dnr 2013/358) approved the study on 28 April 2014. All subjects gave written informed consent. A study physician was available at every study center to handle unexpected findings.

\section{Statistics}

Variables that were not normally distributed were treated as nonparametric (eg, blood cell counts) or were transformed to achieve a normal distribution (log-transformation for $\mathrm{F}_{\mathrm{E}} \mathrm{NO}$ ). Differences between groups, when more than two groups were in the same analysis, were tested with one-way analysis of variance (ANOVA), Kruskal-Wallis test, Pearson $\chi^{2}$-test or Fisher's exact test (comorbidity and medication use). Groupwise differences were tested with unpaired $t$-test, Mann-Whitney $U$ test, Pearson $\chi^{2}$-test or Fisher's exact test. Stata 14.2 (StataCorp LP, College Station, TX, USA), R v.3.4.0 (R Foundation for Statistical Computing, Vienna,
Austria) or SPSS v.24 for Windows (IBM Corporation, Armonk, NY, USA) were used for all statistical calculations. A $p$-value of $<0.05$ was regarded as significant.

\section{Results}

A total of 620 patients were recruited, of whom 571 research subjects were enrolled in the study (Figure 1). In the region of Dalarna, the subjects were recruited from primary care and in Uppsala and Gävleborg, from both primary and secondary care settings.

The characteristics of the subjects classified from the lower risk group A to the higher risk group D according to the GOLD ${ }^{2014}$ are presented in Table 1. Apart from the expected differences in lung function, symptom burden and exacerbation history, there were also differences in BMI, comorbidities and B-Neu. The proportion of subjects who had no regular treatment decreased from group A to $\mathrm{D}(p<0.001)$, while the proportion of subjects on ICS increased from group A to $\mathrm{D}(p<0.001)$.

Changes in classification from the old grading system $\left(\right.$ GOLD $\left.^{2014}\right)$ to the new $\left(G^{20 L D}{ }^{2017}\right)$ are presented in Figure 2. The proportion of subjects who would be reclassified with the new GOLD ${ }^{2017}$ from group $\mathrm{C}$ to A were $53 \%$ and from group $\mathrm{D}$ to $\mathrm{B}$ were $47 \%$. The percentage of subjects who would be reclassified from group $\mathrm{D}$ to $\mathrm{B}$ from the different study centers were $42 \%$ in Uppsala, $41 \%$ in Gävleborg and $63 \%$ in Dalarna $(p=0.03)$. In regard to health care contact, the proportion of subjects who would be reclassified from

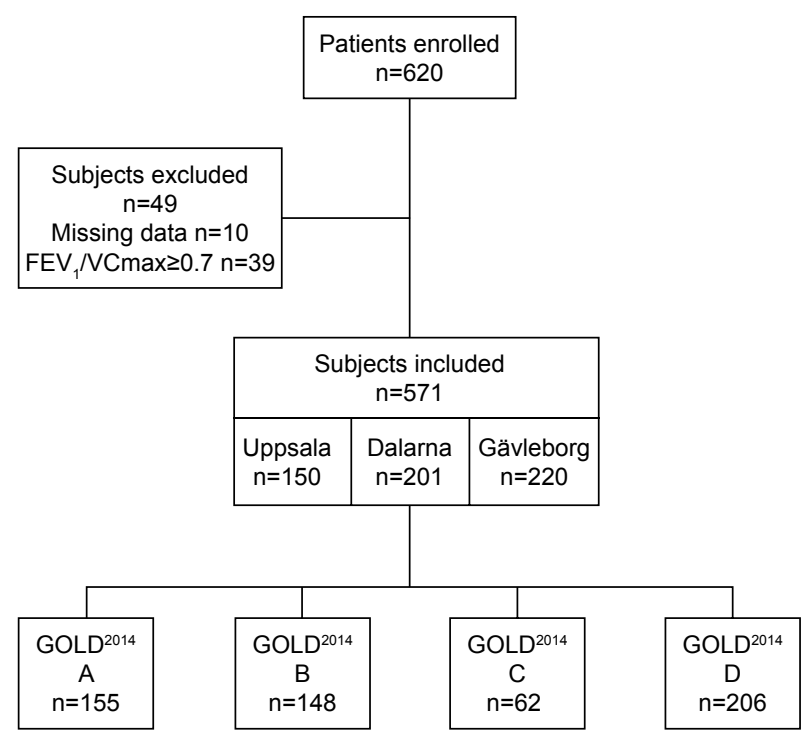

Figure I Flow chart of the inclusion of participants from the central Swedish regions of Dalarna, Gävleborg and Uppsala with the grouping into A-D using GOLD ${ }^{2014}$ guidelines. Abbreviations: $\mathrm{FEV}_{1}$, forced expiratory volume in I second; VCmax, highest vital capacity from slow or forced vital capacity; GOLD, Global Initiative for Chronic Obstructive Lung Disease. 
Table I Characteristics of the subjects assessed by GOLD 2014

\begin{tabular}{|c|c|c|c|c|c|}
\hline GOLD $^{2014}$ & A & B & C & D & $p$-value \\
\hline Subjects, $n$ & 155 & 148 & 62 & 206 & \\
\hline Female, n (\%) & $80(52)$ & $83(56)$ & $39(63)$ & $133(65)$ & 0.07 \\
\hline Age (years) & $68(7)$ & $69(8)$ & $67(9)$ & $69(7)$ & 0.06 \\
\hline Educational level, ${ }^{\mathrm{a}} \mathrm{n}(\%)$ & $34(22)$ & $33(22)$ & $15(24)$ & $37(18)$ & 0.60 \\
\hline Smoking, n (\%) & $50(32)$ & $4 \mid(28)$ & $16(26)$ & $57(28)$ & 0.71 \\
\hline BMI & $26(4)$ & $28(5)$ & $26(5)$ & $26(6)$ & $<0.00 \mathrm{I}$ \\
\hline \multicolumn{6}{|l|}{ Comorbidity, n (\%) } \\
\hline Asthma & $4 \mid(26)$ & $44(30)$ & $25(40)$ & $79(38)$ & 0.048 \\
\hline Chronic bronchitis & $20(13)$ & $55(37)$ & $15(24)$ & $103(50)$ & $<0.00 \mathrm{I}$ \\
\hline Heart disease & $25(16)$ & $37(25)$ & $4(6)$ & $51(25)$ & 0.002 \\
\hline Hypertension & $62(40)$ & $77(52)$ & $23(37)$ & $115(56)$ & 0.005 \\
\hline Diabetes & $12(8)$ & $15(10)$ & $5(8)$ & $22(\mathrm{II})$ & 0.80 \\
\hline Anxiety/depression & $24(15)$ & $43(29)$ & $12(19)$ & $56(27)$ & 0.015 \\
\hline \multicolumn{6}{|l|}{ Lung function } \\
\hline $\mathrm{FEV}_{1}(\%$ predicted) & $68(11)$ & $67(12)$ & $48(16)$ & $43(15)$ & $<0.00 \mathrm{I}$ \\
\hline FVC (\% predicted) & $80(16)$ & $74(14)$ & $66(18)$ & $60(15)$ & $<0.00 \mathrm{I}$ \\
\hline \multicolumn{6}{|l|}{ Inflammatory markers } \\
\hline $\mathrm{F}_{\mathrm{E}} \mathrm{NO}_{50}(\mathrm{ppb})^{\mathrm{b}}$ & $14(13,16)$ & $13(11,15)$ & $12(10,14)$ & $13(12,14)$ & 0.28 \\
\hline B-Neu $\left(10^{9} / L\right)^{b}$ & $4.4(4 . I, 4.6)$ & $4.4(4.2,4.6)$ & $4.7(4.3,5.0)$ & $5.0(4.7,5.2)$ & $<0.001$ \\
\hline B-Eos $\left(10^{9} / \mathrm{L}\right)^{\mathrm{b}}$ & $0.18(0.16,0.20)$ & $0.20(0.18,0.22)$ & $0.16(0.13,0.21)$ & $0.16(0.14,0.18)$ & 0.06 \\
\hline \multicolumn{6}{|l|}{ Treatment, ${ }^{c} \mathrm{n}(\%)$} \\
\hline No treatment ${ }^{d}$ & $58(37)$ & $37(25)$ & $9(15)$ & $16(8)$ & $<0.00 \mathrm{I}$ \\
\hline Bronchodilators $^{e}$ & $42(27)$ & $40(27)$ & $7(\mathrm{II})$ & $24(12)$ & $<0.00 \mathrm{I}$ \\
\hline $\mathrm{ICS}^{\mathrm{f}}$ & $55(36)$ & 7I (48) & $46(74)$ & $166(80)$ & $<0.00 \mathrm{I}$ \\
\hline \multicolumn{6}{|l|}{ Symptom burden } \\
\hline САТ & $6(3)$ & $15(4)$ & $6(3)$ & $18(6)$ & $<0.00 \mathrm{I}$ \\
\hline $\mathrm{mMRC}$ & $0.8(0.7)$ & $\mathrm{I} .7(\mathrm{I} .0)$ & I.I (0.8) & $2.5(1.3)$ & $<0.00 \mathrm{I}$ \\
\hline $\mathrm{CCQ}$ & $0.8(0.5)$ & $1.9(0.8)$ & $0.9(0.5)$ & $2.7(\mathrm{I} . \mathrm{I})$ & $<0.001$ \\
\hline \multicolumn{6}{|l|}{ Exacerbations, n (\%) } \\
\hline Any exacerbations & $29(19)$ & $35(24)$ & $34(55)$ & $136(66)$ & $<0.00 \mathrm{I}$ \\
\hline Hospital admissions & $0(0)$ & $0(0)$ & $8(13)$ & $31(15)$ & $<0.001$ \\
\hline
\end{tabular}

Notes: Data are given in mean (SD). ${ }^{a}$ Defined as at least 3 years in high school. ${ }^{b}$ Geometrical mean ( $\left.95 \% \mathrm{Cl}\right)$. 'Short-acting $\beta_{2}$-agonist and/or short-acting muscarinicantagonist possible. ${ }^{d}$ No treatment or no regular treatment. ${ }^{\mathrm{LABA}}$ and/or LAMA alone or in combination. flCS alone or in any combination with bronchodilators.

Abbreviations: B-Eos, blood eosinophil count; B-Neu, blood neutrophil count; BMI, body mass index; CAT, COPD Assessment Test; CCQ, Clinical COPD Questionnaire; $\mathrm{F}_{\mathrm{E}} \mathrm{NO}_{50}$, exhaled nitric oxide at an exhalation flow of $50 \mathrm{~mL} / \mathrm{s}$; $\mathrm{FEV}$, forced expiratory volume in I second; FVC, forced vital capacity; GOLD, Global Initiative for Chronic Obstructive Lung Disease; ICS, inhaled corticosteroids; LABA, long-acting $\beta 2$-agonist; LAMA, long-acting muscarinic antagonist; mMRC, modified British Medical Research Council.

group $\mathrm{D}$ to $\mathrm{B}$ was higher among those from primary care compared to those from secondary care with $54 \%$ vs $33 \%$, respectively ( $p=0.005)$. No significant differences were found for subjects who would be reclassified from group $\mathrm{C}$ to $\mathrm{A}$

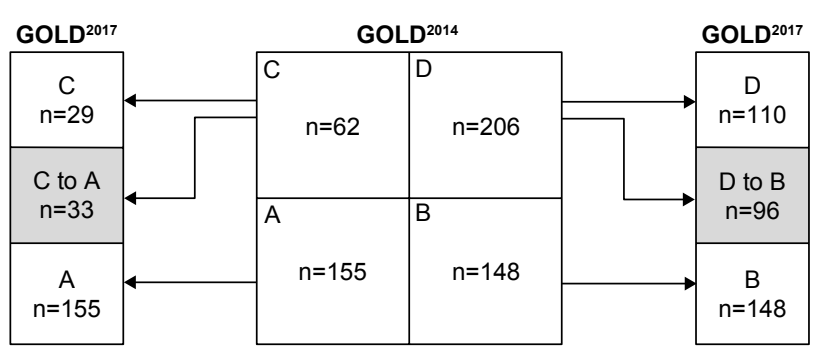

Figure 2 Change in distribution of subjects assessed with GOLD ${ }^{2014}$ and reassessed with GOLD 2017 .

Abbreviation: GOLD, Global Initiative for Chronic Obstructive Lung Disease. with regard to study center or type of health care contact (data not shown).

The characteristics of subjects who with the new grading system would change group from $\mathrm{C}$ to $\mathrm{A}$, would remain in group $\mathrm{A}$ or remain in group $\mathrm{C}$ are shown in Table 2. Apart from the expected differences in lung function and exacerbations in the subjects who would change from group $\mathrm{C}$ to $\mathrm{A}$, there were no differences in the characteristics of the subjects who would change from group $\mathrm{C}$ to A compared to those who would remain in group $\mathrm{C}$.

The characteristics of subjects who after reassessment would change from group D to B, would remain in group B and would remain in group D are shown in Table 3. Apart from the expected differences in lung function and exacerbations, the subjects who would change from group D to B had 
Table 2 Characteristics of the subjects that would remain in group $C$ and $A$ and of those that would change to group $A$ using GOLD2017 instead of GOLD 2014

\begin{tabular}{|c|c|c|c|c|c|}
\hline & $\begin{array}{l}\text { Group C changing } \\
\text { to group A }\end{array}$ & $\begin{array}{l}\text { Group A remaining } \\
\text { in group A }\end{array}$ & $p$-value ${ }^{c}$ & $\begin{array}{l}\text { Group } C \text { remaining } \\
\text { in group } C\end{array}$ & $p$-value ${ }^{c}$ \\
\hline Subjects, $n$ & 33 & 155 & & 29 & \\
\hline Female, n (\%) & $20(6 I)$ & $80(52)$ & 0.44 & $19(66)$ & 0.79 \\
\hline Age (years) & $65(9)$ & $68(7)$ & 0.06 & $69(9)$ & 0.09 \\
\hline Educational level, ${ }^{\mathrm{a}} \mathrm{n}(\%)$ & $7(2 I)$ & $34(22)$ & I & $8(28)$ & 0.77 \\
\hline Smoking, n (\%) & $9(27)$ & $50(32)$ & 0.68 & $7(24)$ & 1 \\
\hline BMI & $25(6)$ & $26(4)$ & 0.25 & $26(4)$ & 0.46 \\
\hline \multicolumn{6}{|l|}{ Comorbidity, n (\%) } \\
\hline Asthma & $12(36)$ & $4 I(26)$ & 0.29 & $13(45)$ & 0.61 \\
\hline Chronic bronchitis & $6(18)$ & $20(13)$ & $0.4 \mathrm{I}$ & $9(31)$ & 0.37 \\
\hline Heart disease & $2(6)$ & $25(16)$ & 0.18 & $2(7)$ & 1 \\
\hline Hypertension & II (33) & $62(40)$ & 0.56 & $12(4 \mid)$ & 0.60 \\
\hline Diabetes & $3(9)$ & $12(8)$ & 0.73 & $2(7)$ & 1 \\
\hline Anxiety/depression & $6(18)$ & $24(15)$ & 0.79 & $6(21)$ & I \\
\hline \multicolumn{6}{|l|}{ Lung function } \\
\hline FEV $(\%$ predicted) & $39(9)$ & $68(\mathrm{II})$ & $<0.001$ & $58(16)$ & $<0.001$ \\
\hline FVC (\% predicted) & $60(14)$ & $80(16)$ & $<0.00$ I & $72(19)$ & 0.008 \\
\hline \multicolumn{6}{|l|}{ Inflammatory markers } \\
\hline $\mathrm{F}_{\mathrm{E}} \mathrm{NO}_{50}(\mathrm{ppb})^{\mathrm{b}}$ & $12(9,15)$ & $14(13,16)$ & 0.13 & $12(9,15)$ & 0.96 \\
\hline B-Neu $\left(10^{9} / L\right)^{b}$ & $4.5(4.0,5.0)$ & $4.4(4.1,4.6)$ & 0.70 & $4.9(4.4,5.4)$ & 0.25 \\
\hline B-Eos $\left(10^{9} / \mathrm{L}\right)^{\mathrm{b}}$ & $0.16(0.12,0.20)$ & $0.18(0.16,0.20)$ & 0.30 & $0.18(0.12,0.26)$ & 0.57 \\
\hline \multicolumn{6}{|l|}{ Symptom burden } \\
\hline CAT & $6(3)$ & $6(3)$ & 0.73 & $6(2)$ & 0.72 \\
\hline $\mathrm{mMRC}$ & $1.00(0.75)$ & $0.83(0.66)$ & 0.17 & $\mathrm{I} .14(0.83)$ & 0.50 \\
\hline CCQ & $0.92(0.55)$ & $0.80(0.50)$ & 0.19 & $0.87(0.50)$ & 0.66 \\
\hline \multicolumn{6}{|l|}{ Exacerbations, n (\%) } \\
\hline Any exacerbations & $8(24)$ & $29(19)$ & 0.47 & $26(90)$ & $<0.001$ \\
\hline Hospital admissions & $0(0)$ & $0(0)$ & I & $8(28)$ & 0.001 \\
\hline
\end{tabular}

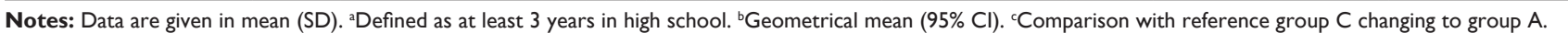
Abbreviations: B-Eos, blood eosinophil count; B-Neu, blood neutrophil count; BMI, body mass index; CAT, COPD Assessment Test; CCQ, Clinical COPD Questionnaire; $\mathrm{F}_{\mathrm{E}} \mathrm{NO}_{50}$, exhaled nitric oxide at an exhalation flow of $50 \mathrm{~mL} / \mathrm{s}$; $\mathrm{FEV}_{1}$, forced expiratory volume in I second; FVC, forced vital capacity; GOLD, Global Initiative for Chronic Obstructive Lung Disease; mMRC, modified British Medical Research Council.

lower BMIs, lower B-Eos counts, higher mMRC grades and higher CCQ scores compared to those who would remain in group B (all $p$-values $<0.05$ ). The subjects who were reassessed and would change from group D to B compared to those who would remain in group D were more often men, of an older age, had more primary versus secondary health care contact, had experienced less asthma, reported less anxiety/depression, had lower B-Neu counts and had lower mMRC, CCQ and CAT scores (all $p$-values $<0.05$ ). No other significant differences were found between the group that would change from D to B and the group that would remain in $\mathrm{B}$.

The association between the staging of COPD based on lung function and risk assessment in groups $\mathrm{A}-\mathrm{D}$ according to the GOLD ${ }^{2014}$ and $\mathrm{GOLD}^{2017}$ classification is presented in Figure 3. With the GOLD ${ }^{2017}$ classification, the proportion of subjects who have an $\mathrm{FEV}_{1}$ below $50 \%$ predicted was $18 \%$ in group A and 39\% in group B. The proportion of subjects who have an $\mathrm{FEV}_{1}$ above $50 \%$ predicted was $69 \%$ in group $\mathrm{C}$ and $44 \%$ in group D.

\section{Discussion}

The main result of the present investigation of a cohort of COPD research subjects from Swedish primary and secondary health care settings is that the change introduced in the 2017 edition of GOLD would lead to the reclassification of approximately half of the subjects from groups $\mathrm{C}$ and $\mathrm{D}$ to A and B, respectively. The reassessed subjects who would change from group D to B were older, to larger extent male, had lower lung function, lower neutrophil count, reported less symptom burden, had fewer exacerbations and were to a larger extent from primary health care settings.

This is one of the first studies, to our knowledge, that shows that the risk assessment from the recent GOLD ${ }^{2017}$ guidelines reduces the number of subjects to approximately half in the high-risk groups $\mathrm{C}$ and $\mathrm{D}$. The rationale behind 
Table 3 Characteristics of the subjects that would remain in group D and B and of those that would change to group B using GOLD2017 instead of GOLD 2014

\begin{tabular}{|c|c|c|c|c|c|}
\hline & $\begin{array}{l}\text { Group D changing } \\
\text { to group B }\end{array}$ & $\begin{array}{l}\text { Group B remaining } \\
\text { in group B }\end{array}$ & $p$-value ${ }^{c}$ & $\begin{array}{l}\text { Group D remaining } \\
\text { in group D }\end{array}$ & $p$-value \\
\hline Subjects, $\mathrm{n}$ & 96 & 148 & & 110 & \\
\hline Female, n (\%) & $54(56)$ & $83(56)$ & I & $79(72)$ & 0.03 \\
\hline Age (years) & $71(8)$ & $69(8)$ & 0.11 & $68(7)$ & 0.01 \\
\hline Educational level, ${ }^{a}$ n (\%) & $21(22)$ & $33(22)$ & I & $16(14)$ & 0.20 \\
\hline Smoking, n (\%) & $24(25)$ & $4 \mathrm{I}(28)$ & 0.66 & $33(30)$ & 0.44 \\
\hline BMI & $26(6)$ & $28(5)$ & $<0.001$ & $27(6)$ & 0.36 \\
\hline \multicolumn{6}{|l|}{ Comorbidity, n (\%) } \\
\hline Asthma & $28(29)$ & $44(30)$ & I & $51(46)$ & 0.01 \\
\hline Chronic bronchitis & $42(44)$ & $55(37)$ & 0.35 & $61(56)$ & 0.12 \\
\hline Heart disease & $19(20)$ & $24(25)$ & 0.50 & $31(28)$ & 0.19 \\
\hline Hypertension & $52(54)$ & $77(52)$ & 0.79 & $63(57)$ & 0.68 \\
\hline Diabetes & $13(13)$ & $15(10)$ & 0.42 & $9(8)$ & 0.26 \\
\hline Anxiety/depression & $19(20)$ & $43(29)$ & 0.13 & $37(34)$ & 0.03 \\
\hline \multicolumn{6}{|l|}{ Lung function } \\
\hline $\mathrm{FEV}_{1}$ (\% predicted) & $38(9)$ & $67(12)$ & $<0.001$ & $48(18)$ & $<0.001$ \\
\hline FVC (\% predicted) & $59(14)$ & $74(14)$ & $<0.001$ & $61(16)$ & 0.20 \\
\hline \multicolumn{6}{|l|}{ Inflammatory markers } \\
\hline $\mathrm{F}_{\mathrm{E}} \mathrm{NO}_{50}(\mathrm{ppb})^{\mathrm{b}}$ & $13(11,16)$ & $13(11,15)$ & 0.75 & $12(11,14)$ & 0.51 \\
\hline B-Neu $\left(10^{9} / \mathrm{L}\right)^{\mathrm{b}}$ & $4.6(4.3,4.9)$ & $4.4(4.2,4.6)$ & 0.23 & $5.3(5.0,5.7)$ & 0.002 \\
\hline B-Eos $\left(10^{9} / \mathrm{L}\right)^{b}$ & $0.16(0.14,0.19)$ & $0.20(0.18,0.22)$ & 0.04 & $0.16(0.13,0.18)$ & 0.70 \\
\hline \multicolumn{6}{|l|}{ Symptom burden } \\
\hline CAT & $16(5)$ & $15(4)$ & 0.09 & $21(7)$ & $<0.001$ \\
\hline $\mathrm{mMRC}$ & $2.3(1.2)$ & $1.9(0.8)$ & $<0.001$ & $2.7(1.3)$ & 0.01 \\
\hline $\mathrm{CCQ}$ & $2.4(1.0)$ & I.8 (I.I) & $<0.001$ & $2.9(1.2)$ & $<0.001$ \\
\hline \multicolumn{6}{|l|}{ Exacerbations, n (\%) } \\
\hline Any exacerbations & $25(26)$ & $35(4)$ & 0.79 & $110(100)$ & $<0.001$ \\
\hline Hospital admissions & $0(0)$ & $0(0)$ & I & $32(29)$ & $<0.001$ \\
\hline
\end{tabular}

Notes: Data are given in mean (SD). a Defined as at least 3 years in high school. ${ }^{b}$ Geometrical mean $\left(95 \%\right.$ Cl). ${ }^{c}$ Comparison with reference group D changing to group B. Abbreviations: B-Eos, blood eosinophil count; B-Neu, blood neutrophil count; BMI, body mass index; CAT, COPD Assessment Test; CCQ, Clinical COPD Questionnaire; $\mathrm{F}_{\mathrm{E}} \mathrm{NO}_{50}$, exhaled nitric oxide at an exhalation flow of $50 \mathrm{~mL} / \mathrm{s}$; $\mathrm{FEV}$, forced expiratory volume in I second; FVC, forced vital capacity; GOLD, Global Initiative for Chronic Obstructive Lung Disease; mMRC, modified British Medical Research Council.

the change in classification between GOLD ${ }^{2014}$ and GOLD 2017 was to base risk assessment and treatment algorithms on symptoms and exacerbation history only. Lung function has been eliminated from the risk evaluation since a low lung function is not a marker of a rapid lung function decline. Lange et $\mathrm{al}^{13}$ reported two trajectories of lung function for subjects with low $\mathrm{FEV}_{1}$ : one with a more aggressive disease scenario with a rapid lung function decline starting from a normal level and one with a normal decline but starting from a low lung function. That a large portion of subjects from primary health care settings would be reclassified to a lower risk group possibly reflects the fact that those primary care subjects classified with GOLD ${ }^{2014}$ were classified in group D more likely because of poorer lung function and not exacerbation. This is in line with results from primary health care settings in the UK where $70 \%$ of the subjects with $\mathrm{FEV}_{1}<50 \%$ predicted had a low exacerbation risk profile. ${ }^{14}$
A recent Swedish study reported that approximately half of the COPD subjects from secondary care in groups $C$ and D according to GOLD ${ }^{2014}$ were frequent exacerbators. ${ }^{15}$

\section{Gender}

In our study, there were more female subjects than male subjects. This is in line with other studies of COPD patients in Sweden, ${ }^{16,17}$ Norway ${ }^{18}$ and the Netherlands, ${ }^{19}$ showing that the prevalence of the disease in women has risen and become more equalized with that of men. The effects of the classification change in this investigation showed that a higher proportion of females, $72 \%$, would remain in group D. This could reflect that more women with COPD in Sweden have a more severe form of disease. ${ }^{20}$ Moreover, it could be that anxiety/depression, which also has a relationship with a higher exacerbation rate, is more prevalent in women than in men, as suggested by Di Marco et al. ${ }^{21}$ 

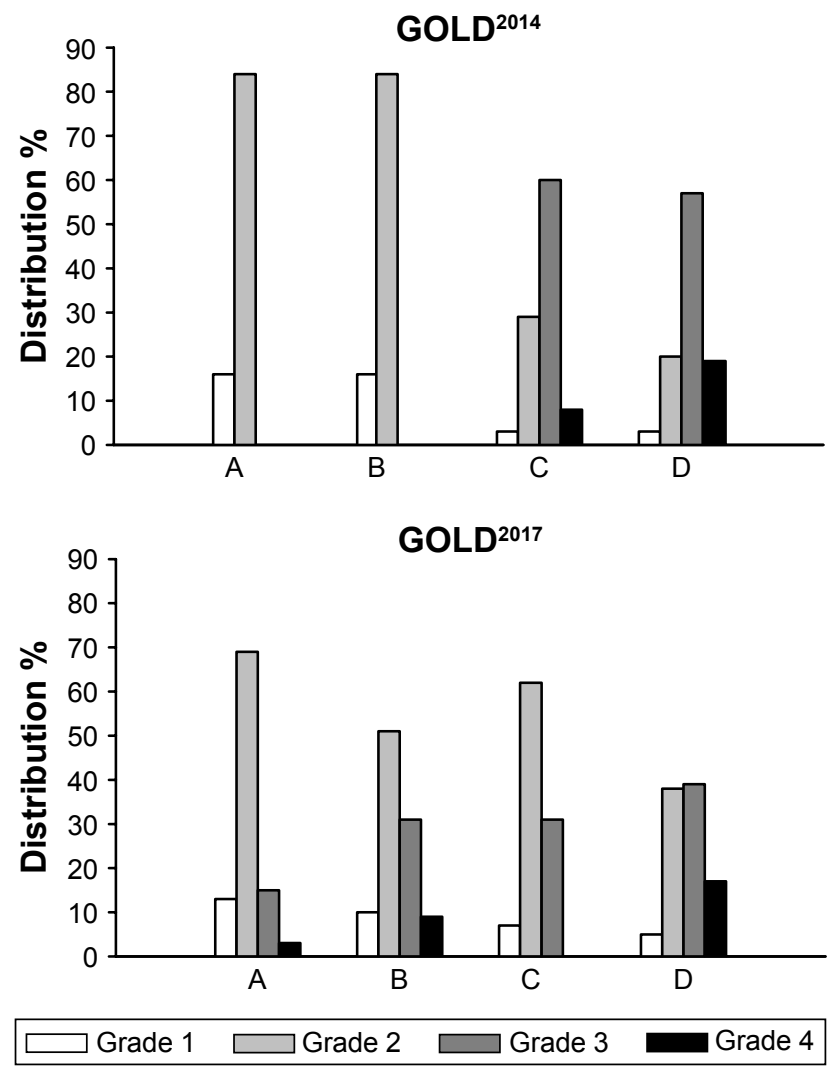

Figure 3 Change in distribution of airflow limitations in GOLD 2014 (upper panel) and GOLD 2017 A-D classification (lower panel).

Note: GOLD grade I $\geq 80 \mathrm{FEV} \%$ predicted, GOLD grade $250-79 \mathrm{FEV}, \%$ predicted, GOLD grade 3 30-49 $\mathrm{FEV}, \%$ predicted and GOLD grade $4<30 \mathrm{FEV} \%$ predicted. Abbreviations: $\mathrm{FEV}_{1}$, forced expiratory volume in I second; GOLD, Globa Initiative for Chronic Obstructive Lung Disease.

\section{Comorbidity}

Interestingly, a higher proportion of subjects who would remain in group D compared to those who would change to group B had concomitant asthma and anxiety/depression. Previous studies suggest that there is a relationship between anxiety symptoms and an increased risk of rehospitalization for COPD patients. ${ }^{22} \mathrm{~A}$ recently published article reveals that depressive symptoms in patients with COPD are associated with exacerbations and hospital admissions. ${ }^{23}$ Several studies have shown that patients with both asthma and COPD have a more severe form of the disease. ${ }^{24,25}$ Surprisingly, no differences were found with regard to cardiac comorbidity between subjects who would be reclassified from group $D$ to $\mathrm{B}$ and subjects who would remain to be classified in group D. This might be due to the fact that our definition of cardiac comorbidity included both atrial fibrillation and angina pectoris along with heart failure comorbidity, which appears to have the strongest relationship with the risk for exacerbation. ${ }^{26}$

\section{Inflammatory markers}

Several studies had suggested that increased levels of blood eosinophils are related with a higher likelihood of COPD exacerbations..$^{27,28}$ However, in the present study, no difference with regard to the $\mathrm{GOLD}^{2017}$ group or a reclassification could be found. This is in line with recent studies that failed to demonstrate an association of blood eosinophilia with COPD exacerbation rates and prognosis. ${ }^{29}$ Blood neutrophils, on the other hand, were elevated in subjects who would remain in group D compared with subjects who would change from group D to B. This is in line with previous studies suggesting that increased blood neutrophils have a relationship with exacerbations. $^{30}$

\section{Frequent exacerbations}

Even though there is a strong relationship between frequent exacerbations and decline in lung function, ${ }^{31}$ there are also patients with relatively mild forms of airway obstructions who are frequent exacerbators. ${ }^{32}$ In our investigation, there is a large proportion of subjects in $\mathrm{GOLD}^{2017}$ groups A and B with low lung function. That this group also includes subjects with rapid lung function decline and a higher risk for exacerbation needs to be established with further studies.

\section{Strengths and weaknesses}

This is a large study with COPD patients from both primary and secondary health care settings with few exclusion criteria generating a high level of generalizability. This is one of the first studies investigating, in a real-life setting, the characteristics of the subjects who would change from groups $\mathrm{C}$ and $\mathrm{D}$ to A and B, respectively. A weakness is that this analysis is based on a cross-sectional analysis and we would be unable to say anything about the prognostic implications relative to the eventual changes in the severity classification. Another weakness is that data regarding medication use, comorbidity and exacerbation rate were based on questionnaires.

\section{Conclusion}

This study shows that a high proportion of patients will be reclassified after the implementation of the new 2017 GOLD guidelines. The effects of the reclassification and eventual changes in treatment for disease control and symptom burden need further investigation.

\section{Acknowledgments}

The authors wish to thank the personnel at the Dalarna, Gävleborg and Uppsala research units and Robin Quell for 
proofreading and editing this manuscript. This study was funded by the Uppsala-Örebro Regional Research Council, Center for Research \& Development, Uppsala University/ Region Gävleborg, Center for Clinical Research, Uppsala University, County Council Dalarna, The Swedish Heart-Lung Foundation and The Swedish Heart and Lung Association.

\section{Author contributions}

$\mathrm{MH}$, JS and AM had full access to the study data and take full responsibility for the integrity of the data and the accuracy of the analysis. $\mathrm{MH}, \mathrm{AM}, \mathrm{BS}, \mathrm{KL}, \mathrm{CJ}, \mathrm{KB}$ and $\mathrm{HH}$ contributed to the study design and the writing of the manuscript. All authors contributed toward the data analysis, drafting and critical revision of the paper. All have given final approval of the version to be published and agree to be accountable for all aspects of the work.

\section{Disclosure}

The authors report no conflicts of interest in this work.

\section{References}

1. Pauwels RA, Buist AS, Ma P, Jenkins CR, Hurd SS, Committee GS. Global strategy for the diagnosis, management, and prevention of chronic obstructive pulmonary disease: National Heart, Lung, and Blood Institute and World Health Organization Global Initiative for Chronic Obstructive Lung Disease (GOLD): executive summary. Respir Care. 2001;46(8):798-825.

2. Bafadhel M, McKenna S, Terry S, et al. Acute exacerbations of chronic obstructive pulmonary disease: identification of biologic clusters and their biomarkers. Am J Respir Crit Care Med. 2011;184(6):662-671.

3. Seemungal TA, Donaldson GC, Paul EA, Bestall JC, Jeffries DJ, Wedzicha JA. Effect of exacerbation on quality of life in patients with chronic obstructive pulmonary disease. Am J Respir Crit Care Med. 1998;157(5 pt 1):1418-1422.

4. Jones PW, Harding G, Berry P, Wiklund I, Chen WH, Kline Leidy N. Development and first validation of the COPD Assessment Test. Eur Respir J. 2009;34(3):648-654.

5. Wedzicha JA, Bestall JC, Garrod R, Garnham R, Paul EA, Jones PW. Randomized controlled trial of pulmonary rehabilitation in severe chronic obstructive pulmonary disease patients, stratified with the MRC dyspnoea scale. Eur Respir J. 1998;12(2):363-369.

6. Mahler DA, Rosiello RA, Harver A, Lentine T, McGovern JF, Daubenspeck JA. Comparison of clinical dyspnea ratings and psychophysical measurements of respiratory sensation in obstructive airway disease. Am Rev Respir Dis. 1987;135(6):1229-1233.

7. Vogelmeier CF, Criner GJ, Martinez FJ, et al. Global strategy for the diagnosis, management, and prevention of chronic obstructive lung disease 2017 report. GOLD executive summary. Am J Respir Crit Care Med. 2017;195(5):557-582.

8. van der Molen T, Willemse BW, Schokker S, ten Hacken NH, Postma DS, Juniper EF. Development, validity and responsiveness of the Clinical COPD Questionnaire. Health Qual Life Outcomes. 2003;1:13.

9. Miller MR, Hankinson J, Brusasco V, et al. Standardisation of spirometry. Eur Respir J. 2005;26(2):319-338.

10. Hedenström H, Malmberg P, Agarwal K. Reference values for lung function tests in female. Regression equations with smoking variables. Bull Eur Physiopathol Respir. 1985;21:551-557.

11. Hedenström H, Malmberg P, Fridriksson HV. Reference values for pulmonary function test in men: regression equations which include tobacco smoking variables. Upsala J Med Sci. 1986;91:299-310.
12. American Thoracic Society; European Respiratory Society. ATS/ERS recommendations for standardized procedures for the online and offline measurement of exhaled lower respiratory nitric oxide and nasal nitric oxide, 2005. Am J Respir Crit Care Med. 2005;171(8):912-930.

13. Lange P, Celli B, Agusti A, et al. Lung-function trajectories leading to chronic obstructive pulmonary disease. $N$ Engl J Med. 2015;373(2): 111-122.

14. Haughney J, Gruffydd-Jones K, Roberts J, Lee AJ, Hardwell A, McGarvey L. The distribution of COPD in UK general practice using the new GOLD classification. Eur Respir J. 2014;43(4):993-1002.

15. Sundh J, Janson C, Johansson G, et al. Characterization of secondary care for COPD in Sweden. Eur Clin Respir J. 2017;4(1):1270079.

16. Lisspers K, Johansson G, Jansson C, et al. Improvement in COPD management by access to asthma/COPD clinics in primary care: data from the observational PATHOS study. Respir Med. 2014;108(9):1345-1354.

17. Sundh J, Montgomery S, Hasselgren M, et al. Change in health status in COPD: a seven-year follow-up cohort study. NPJ Prim Care Respir Med. 2016;26:16073

18. Waatevik M, Skorge TD, Omenaas E, Bakke PS, Gulsvik A, Johannessen A. Increased prevalence of chronic obstructive pulmonary disease in a general population. Respir Med. 2013;107(7):1037-1045.

19. Bischoff EW, Schermer TR, Bor H, Brown P, van Weel C, van den Bosch WJ. Trends in COPD prevalence and exacerbation rates in Dutch primary care. Br J Gen Pract. 2009;59(569):927-933.

20. Ställberg B, Janson C, Johansson G, et al. Management, morbidity and mortality of COPD during an 11-year period: an observational retrospective epidemiological register study in Sweden (PATHOS). Prim Care Respir J. 2014;23(1):38-45.

21. Di Marco F, Verga M, Reggente M, et al. Anxiety and depression in COPD patients: the roles of gender and disease severity. Respir Med. 2006; 100(10):1767-1774.

22. Gudmundsson G, Gislason T, Janson C, et al. Risk factors for rehospitalisation in COPD: role of health status, anxiety and depression. Eur Respir J. 2005;26(3):414-419.

23. Yohannes AM, Mulerova H, Lavoie K, et al. The association of depressive symptoms with rates of acute exacerbations in patients with COPD: results from a 3-year longitudinal follow-up of the ECLIPSE cohort. J Am Med Dir Assoc. 2017;18(11):955.e6-959.e6.

24. Ekerljung L, Mincheva R, Hagstad S, et al. Prevalence, clinical characteristics and morbidity of the Asthma-COPD overlap in a general population sample. J Asthma. Epub 2017 Jul 11:1-9. doi:10.1080/02770903.

25. Alshabanat A, Zafari Z, Albanyan O, Dairi M, FitzGerald JM. Asthma and COPD overlap syndrome (ACOS): a systematic review and meta analysis. PLoS One. 2015;10(9):e0136065.

26. Westerik JA, Metting EI, van Boven JF, Tiersma W, Kocks JW, Schermer TR. Associations between chronic comorbidity and exacerbation risk in primary care patients with COPD. Respir Res. 2017; 18(1):31.

27. Couillard S, Larivee P, Courteau J, Vanasse A. Eosinophils in COPD exacerbations are associated with increased readmissions. Chest. 2017;151(2):366-373.

28. Vedel-Krogh S, Nielsen SF, Lange P, Vestbo J, Nordestgaard BG. Blood eosinophils and exacerbations in chronic obstructive pulmonary disease. The Copenhagen General Population Study. Am J Respir Crit Care Med. 2016;193(9):965-974.

29. Zysman M, Deslee G, Caillaud D, et al. Relationship between blood eosinophils, clinical characteristics, and mortality in patients with COPD. Int J Chron Obstruct Pulmon Dis. 2017;12:1819-1824.

30. Velthove KJ, Bracke M, Souverein PC, et al. Identification of exacerbations in obstructive lung disease through biomarkers. Biomarkers. 2009;14(7):523-528.

31. Makris D, Moschandreas J, Damianaki A, et al. Exacerbations and lung function decline in COPD: new insights in current and ex-smokers. Respir Med. 2007;101(6):1305-1312.

32. Hurst JR, Vestbo J, Anzueto A, et al; Evaluation of COPD Longitudinally to Identify Predictive Surrogate Endpoints (ECLIPSE) Investigators. Susceptibility to exacerbation in chronic obstructive pulmonary disease. $N$ Engl J Med. 2010;363(12):1128-1138. 
International Journal of COPD

\section{Publish your work in this journal}

The International Journal of COPD is an international, peer-reviewed journal of therapeutics and pharmacology focusing on concise rapid reporting of clinical studies and reviews in COPD. Special focus is given to the pathophysiological processes underlying the disease, intervention programs, patient focused education, and self management protocols.

This journal is indexed on PubMed Central, MedLine and CAS. The manuscript management system is completely online and includes a very quick and fair peer-review system, which is all easy to use. Visit http://www.dovepress.com/testimonials.php to read real quotes from published authors 